\title{
Primary Sarcoma of the Left Atrium
}

\author{
E. B. RAFTERY, S. AHMED, and M. V. BRAIMBRIDGE \\ From the Cardiac Department and Cardiac Surgical Unit, St. Thomas's Hospital, London S.E.I
}

Primary tumours of the heart are rare (Yater, 1931) and can present difficult diagnostic problems. Not only do they simulate valvular disease of the heart, but they are sometimes accompanied by a non-specific syndrome of fever, anæmia, clubbing of the fingers and toes, hæmoptysis, and a raised erythrocyte sedimentation rate (ESR). This may be very difficult to distinguish from subacute bacterial endocarditis, pulmonary tuberculosis, or carcinoma of the bronchus, and has only been described in association with benign myxomas of the left atrium (Goodwin et al., 1962). This report is of a left atrial sarcoma which presented in this way.

\section{Case Report}

The patient, a 53-year-old lorry driver, presented in May 1963 with a two-week history of exertional dyspncea and ankle swelling. There was no past history of rheumatic fever or chorea, and he had always been in good health before the onset of these symptoms. On examination, he was wasted, and in congestive heart failure. The pulse was in sinus rhythm, with a rate of 100 a minute, and a blood pressure of $150 / 80 \mathrm{~mm}$. Hg. There was marked clubbing of the fingers and toes which the patient insisted was of recent appearance, but there were no splinter hæmorrhages or splenomegaly. There was clinical evidence of both right and left ventricular hypertrophy. On auscultation, there was a loud and widely split first heart sound followed by a pansystolic murmur. The pulmonary component of the second heart sound was accentuated, and was followed by a soft opening snap. A short mid-diastolic murmur was audible at the apex (Fig. 1). The electrocardiogram was within normal limits and the chest radiograph showed enlargement of the heart, particularly the left atrium, and pulmonary œdema. At this time the hæmoglobin was 98 per cent, with a white count of 9,000 (normal differential) and an ESR of $40 \mathrm{~mm}$. (Westergren). Blood cultures were negative.

He made an excellent symptomatic response to digitalis and diuretic therapy, and returned to work after three weeks. He presented again one month later in severe congestive heart failure, with a cough, brisk hæmoptysis, and a low-grade fever. A large right- sided pleural effusion had developed and the electrocardiogram showed a shift of axis to the right. The mid-diastolic murmur was less obvious than on his previous admission, but could not be made to vary with positional changes. The hæmoglobin was 90 per cent with a white cell count of 9,150 (64\% neutrophils, $15 \%$ lymphocytes, $15 \%$ eosinophils, $6 \%$ monocytes) and an ESR of $35 \mathrm{~mm}$. Six blood cultures were negative, and no pathogens or malignant cells could be found in numerous specimens of sputum. Pleural aspiration revealed a fluid with the characteristics of a transudate, containing only a few mesothelial cells and lymphocytes. The total serum proteins were $6.6 \mathrm{~g} . / 100 \mathrm{ml}$. (albumin $5.1 \mathrm{~g}$., globulin $1.5 \mathrm{~g}$.), and electrophoresis showed only a small increase in the $\beta$-globulin level. Six lupus erythematosus cell preparations were negative. Tomograms of the chest failed to reveal any localized lesion, and bronchoscopy revealed only slight cedema of the bronchial mucous membrane.

Despite a six-week course of intramuscular penicillin (six million units daily), the fever and hæmoptysis persisted. He responded only slowly to intensive diuretic therapy, and the haemoglobin fell steadily to 53 per cent with a serum iron of $53 \mu \mathrm{g} . / 100 \mathrm{ml}$. The sternal marrow cells showed gross iron deficiency. The anæmia responded promptly to a course of intravenous iron. The white cell count continued to be within normal limits except for a slight eosinophilia ranging from 4 to 15 per cent. The ESR varied from 12 to $40 \mathrm{~mm}$.

Cardiac catheterization in January 1964 showed the mean pulmonary wedge pressure to be $25 \mathrm{~mm}$. $\mathrm{Hg}$ and the pulmonary artery pressure to be $56 / 28 \mathrm{~mm}$. $\mathrm{Hg}$. Selective pulmonary angiography revealed marked narrowing of the small pulmonary arteries, but the left atrium failed to opacify despite prolonged observation. In spite of this, a clinical diagnosis of left atrial myxoma was made, and the patient was offered the opportunity of surgery. He refused, and returned home. Two months later he presented again in severe congestive failure, and after a further period of intensive treatment was submitted to thoracotomy.

Operation (July 7). Before the thorax was opened, a supportive bypass from the right atrium to femoral artery was made ready to drain the atrium through a catheter inserted through the femoral vein. Right atrial 

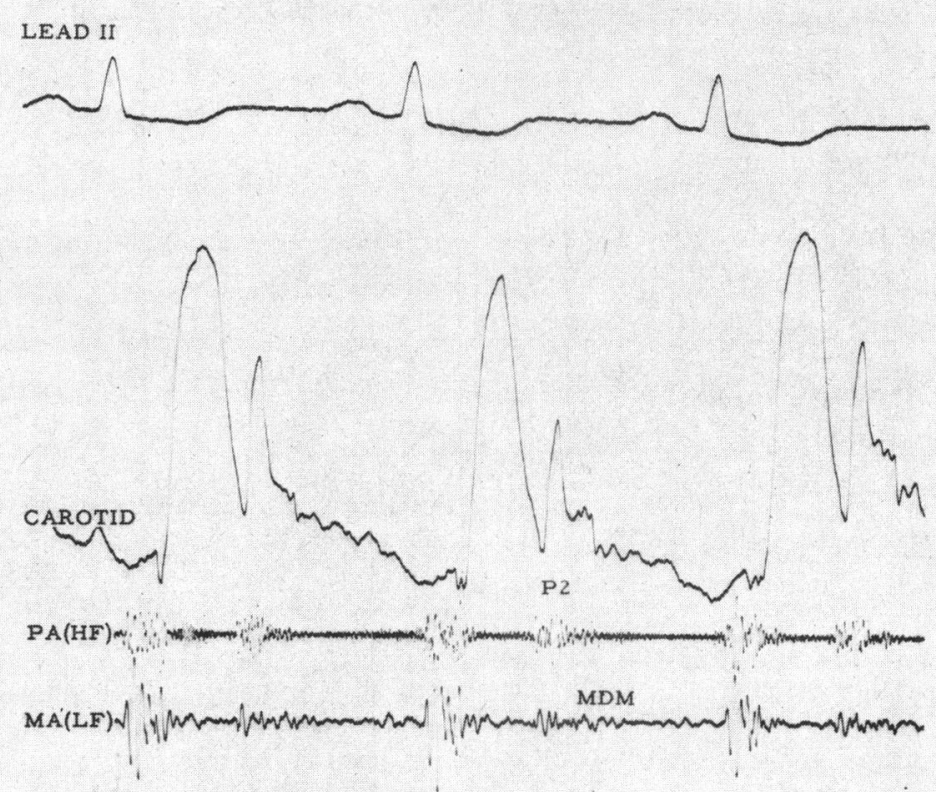

B
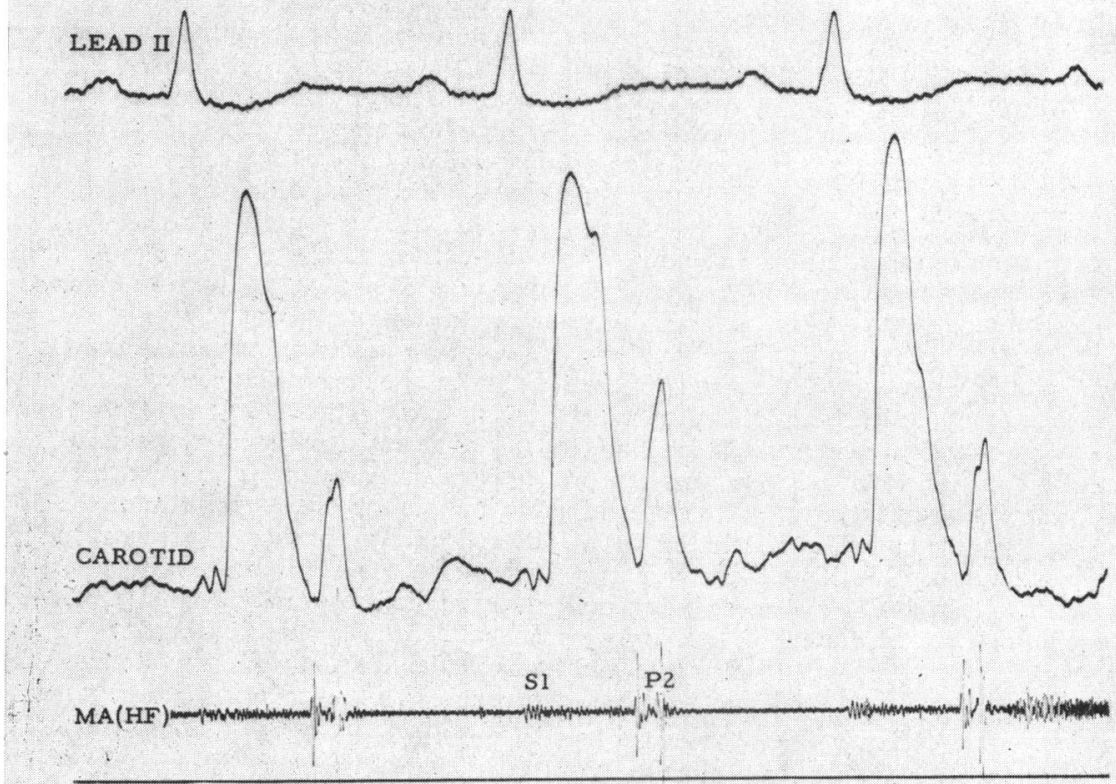

FIG. 1.-Phonocardiograms before (A) and after (B) removal of the tumour. Note that the soft opening snap and mid-diastolic murmur in (A) are not evident in (B). PA(HF), pulmonary area, high frequency; MA(LF), mitral area, low frequency; $M A(H F)$, mitral area, high frequency; S1, first heart sound; $\mathrm{P} 2$, pulmonary component of the second heart sound; MDM, mid-diastolic murmur. 
blood could be passed through the Osborn-BramsonGerbode oxygenator and returned to the femoral artery. This technique was necessary because of the poor condition of the patient, which, it was felt, would deteriorate further during cardiac manipulation.

A left thoracotomy was performed through the 5th intercostal space dividing the sternum. The lung was not stiff and there was no septal œedema or left pleural fluid; $1,200 \mathrm{ml}$. were aspirated from the right pleura. A firm mass in the right transverse fissure was thought to be an encysted effusion. The pericardium was opened and the left atrium was shown to be much enlarged.

No pressure measurements were made from the left side of the heart because of the danger of dislodging tumour. The blood pressure slowly deteriorated and the venous oxygen saturation fell. Femoro-femoral bypass was, therefore, begun, with immediate improvement in blood pressure and venous oxygen saturation, and the heart was explored. A firm sessile tumour was felt on the medial wall of the left atrium, attached to the valve ring. There was moderate mitral incompetence.

A cannula was inserted in the right atrial appendage and joined to a $\mathrm{Y}$ piece in the femoral venous line. Bypass was made total without interruption, a left ventricular vent was inserted and the heart was fibrillated electrically. The left atrium was opened and the tumour was seen as a firm, yellow, sessile mass, 6 by $3 \mathrm{~cm}$. in diameter, quite unlike a myxoma, extending down through the valve ring which had made a waist on the tumour by compression. The base of the tumour was attached to the medial part of the mitral valve ring above the commissure over an area 2.5 by $1.5 \mathrm{~cm}$. The valve cusps were normal. There was a second small tumour, $1 \mathrm{~cm}$. in diameter, in the orifice of the left inferior pulmonary vein.

Both tumours were removed as far as possible and their bases scraped. Total removal was obviously impracticable. The left atrium was closed, the heart restarted with a single D.C. shock and bypass was discontinued. The chest was closed with pleural drainage and a tracheostomy performed for artificial respiration.

Post-operative Course. The patient's post-operative progress was slow but uninterrupted. Artificial respiration was discontinued after five days.

Radiotherapy was given in the Radiotherapy Department of St. Thomas's Hospital with cobalt 60 teletherapy to left atrium and upper mediastinum. A tumour dose of 5,000 r. was given in 12 treatments over 28 days.

When seen in the out-patient department in October 1964, he was considerably improved though still with some cough and effort intolerance. He was in sinus rhythm, with a jugular venous pressure of $2 \mathrm{~cm}$.; on auscultation there was an early systolic murmur but the opening snap had disappeared (Fig. 1). He was recatheterized in March 1965, when the mean pulmonary wedge pressure was $3 \mathrm{~mm}$. $\mathrm{Hg}$.

A large opacity had appeared at the right hilum and a smaller one at the left apex. He was given a second course of radiotherapy to these opacities, but slowly deteriorated and died of bronchopneumonia without any clinical evidence of heart failure. At necropsy, the heart was found to be completely free of tumour, though a little scarring could be seen on the medial wall of the left atrium. Large secondary deposits were present in both lungs, but there was no obvious tumour in the pulmonary veins or arteries.

Pathological Specimen. The main tumour was 6 by $3 \mathrm{~cm}$. with a central waist. The second tumour was 1 $\mathrm{cm}$. in diameter. Histologically, both were undifferentiated sarcomata with numerous large strap-like cells, some multinucleated, invading the atrial wall (Fig. 2).
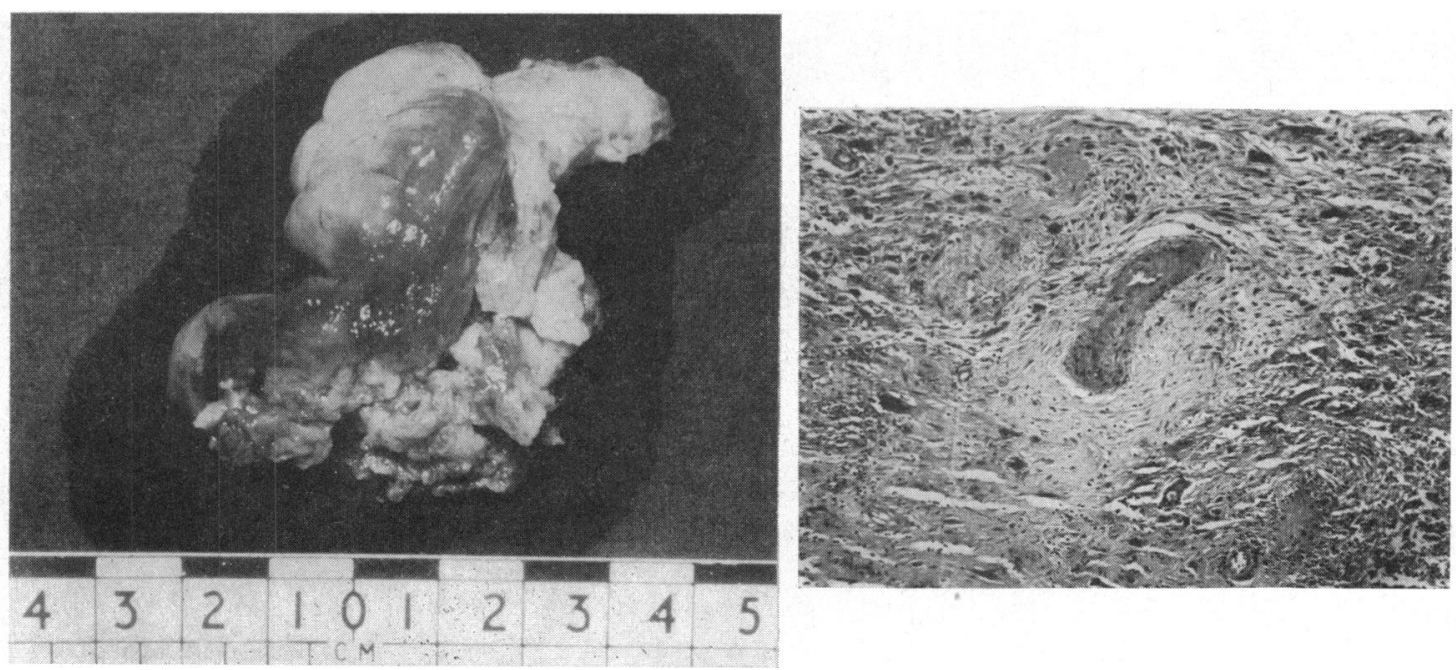

FIG. 2.-Macroscopical and microscopical appearances of the tumour. Note the pleomorphic appearance with large numbers of strap-like cells. Special staining failed to produce any evidence of cross-striation. 
There was some endocardial thrombus overlying part of the growth, but no evidence of a rhabdomyosarcoma, special stains failing to reveal any cross-striations. The appearances suggested a primary rather than a secondary growth because of the diffuse infiltration of the heart wall.

\section{Discussion}

This case report illustrates the difficulty which may be experienced in diagnosing cardiac tumours. The auscultatory sign most commonly associated with tumours is a mid-diastolic murmur which varies with positional changes and simulates mitral stenosis. In this case the signs were suggestive of mitral incompetence (Wittenstein et al., 1959), and the murmur did not vary because the tumour was fixed in the valve orifice. The origin of the "opening snap" is not clear, but it has been suggested that it is produced by the movement of the tumour during atrial systole (Abbott, Warshawski, and Cobbs, 1962), and the fact that it disappears after the tumour is removed supports this suggestion.

Malignant cardiac tumours usually present with the physical signs of pericardial effusion, and the diagnosis is most commonly made by examination of aspirated fluid (Johnson and Stokes, 1964; Zemansky, 1928). This is clearly a function of the way in which the tumour spreads, and previous necropsy reports confirm that most grow into the pericardium and not into the atrial cavity (Yater, 1931). Pascuzzi et al. (1957) described a rhabdomyosarcoma which encroached upon the atrial cavity and was associated with hypertrophic osteoarthropathy. No other case of malignant tumour has been reported as having any symptoms of systemic disease. It seems likely that this syndrome may occur with any tumour that encroaches upon the chambers of the heart, but it has been associated particularly with myxomas because they are commoner than the exceedingly rare primary malignant tumours. Furthermore, the rapid growth of malig- nant tumours makes early pericardial involvement and death more common than valve obstruction and the systemic symptoms which seem to be associated with it.

\section{Summary}

A case is reported of primary sarcoma of the left atrium presenting as mitral incompetence and intractable heart failure. The tumour was associated with fever, anæmia, clubbing of fingers and toes, and a raised ESR, a syndrome that has previously been described in association only with benign primary tumours. The tumour was partially removed with the aid of extracorporeal circulation, and the residue was treated with radiotherapy. At necropsy there was no macroscopic evidence of the primary tumour, but large secondary deposits were present in both lungs.

Thanks are due to Dr. Raymond Daley for permission to publish this case.

\section{References}

Abbott, O. A., Warshawski, F. E., and Cobbs, B. W. (1962). Primary tumors and pseudotumors of the heart. Ann. Surg., 155, 855.

Goodwin, J. G., Stanfield, C. A., Steiner, R. E., Bentall, H. H., Sayed, H. M., Bloom, V. R., and Bishop, M. B. (1962). Clinical features of left atrial myxoma. Thorax, 17, 91.

Johnson, A. G., and Stokes, J. F. (1964). Fibrosarcoma of the heart diagnosed during life. Brit. med. F., 1, 480.

Pascuzzi, C. A., Parkin, T. W., Bruwer, A. J., and Edwards, J. E. (1957). Hypertrophic osteoarthropathy associated with primary rhabdomyosarcoma of the heart. Proc. Mayo Clin., 32, 30.

Wittenstein, G. J., Grow, J. B., Hoffman, M. S., Gensini, G. G., and Denst, J. (1959). "Myxoma" of the left atrium simulating pure mitral insufficiency. Surgery, 45, 981 .

Yater, W. M. (1931). Tumors of the heart and pericardium. Arch. intern. Med., 48, 627.

Zemansky, A. P. (1928). The examination of fluids for tumor cells. Amer. F. med. Sci., 175, 489. 